This item was submitted to Loughborough's Research Repository by the author.

Items in Figshare are protected by copyright, with all rights reserved, unless otherwise indicated.

\title{
The margin for error when releasing the asymmetric bars for dismounts
}

PLEASE CITE THE PUBLISHED VERSION

PUBLISHER

(c) Human Kinetics, Inc.

VERSION

AM (Accepted Manuscript)

LICENCE

CC BY-NC-ND 4.0

REPOSITORY RECORD

Hiley, Michael J., and Maurice R. Yeadon. 2019. "The Margin for Error When Releasing the Asymmetric Bars for Dismounts”. figshare. https://hdl.handle.net/2134/6052. 
This item was submitted to Loughborough's Institutional Repository (https://dspace.lboro.ac.uk/) by the author and is made available under the following Creative Commons Licence conditions.

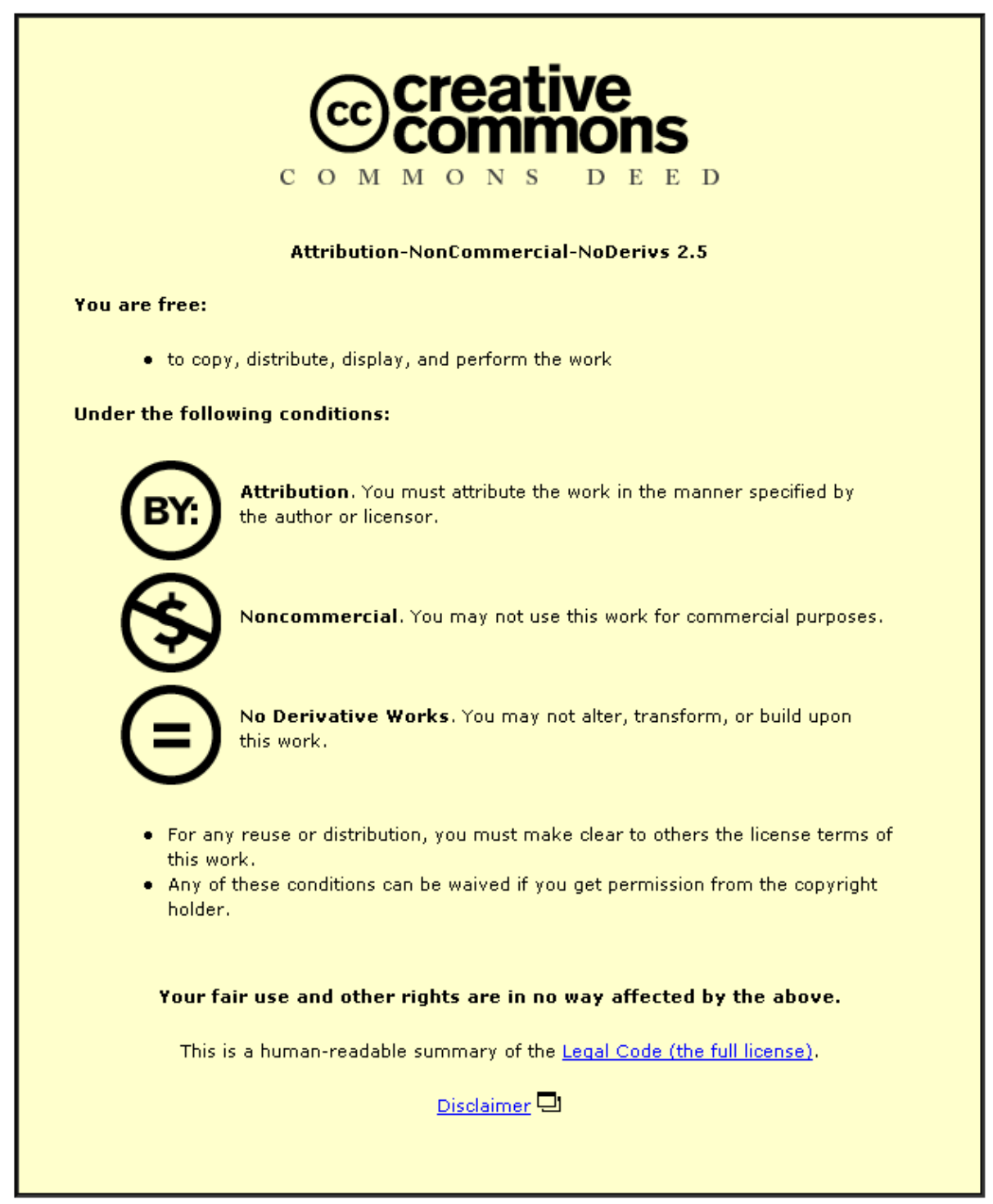

For the full text of this licence, please go to: http://creativecommons.org/licenses/by-nc-nd/2.5/ 


\title{
The margin for error when releasing the asymmetric bars for dismounts
}

\author{
Michael J. Hiley and Maurice R. Yeadon
}

School of Sport and Exercise Sciences, Loughborough University, Loughborough, UK

\begin{abstract}
It has previously been shown that male gymnasts using the "scooped" giant circling technique were able to flatten the path followed by their mass centre resulting in a larger margin for error when releasing the high bar (Hiley and Yeadon, 2003a). The circling technique prior to performing double layout somersault dismounts from the asymmetric bars in Women's Artistic Gymnastics appears to be similar to the "traditional” technique used by some male gymnasts on the high bar. It was speculated that as a result the female gymnasts would have margins for error similar to those of male gymnasts who use the traditional technique. However, it is unclear how the technique of the female gymnasts is affected by the need to avoid the lower bar. A four segment planar simulation model of the gymnast and upper bar was used to determine the margins for error when releasing the bar for nine double layout somersault dismounts at the Sydney 2000 Olympic Games. The elastic properties of the gymnast and bar were modelled using damped linear springs. Model parameters, primarily the inertia and spring parameters, were optimised to obtain a close match between simulated and actual performances in terms of rotation angle $\left(1.2^{\circ}\right)$, bar displacement $(0.011 \mathrm{~m})$ and release velocities $(<1 \%)$. Each matching simulation was used to determine the time window around the actual point of release for which the model had appropriate release parameters to complete the dismount successfully. The margins for error of the nine female gymnasts (release window 43 - $102 \mathrm{~ms}$ ) were comparable with those of the three male gymnasts using the traditional technique (release window $79-84$ $\mathrm{ms})$.
\end{abstract}

Keywords : gymnastics, simulation, release window, angular momentum

\section{Introduction}

The double layout somersault dismount is performed in competition by male gymnasts from the high bar and female gymnasts from the asymmetric bars (Figure 1). In both cases the gymnast uses the preceding backward giant circle to generate sufficient angular momentum and flight to complete the required number of somersaults and to travel safely away from the bar. However, during giant circles leading up to a dismount from the asymmetric bars (a-bars) a female gymnast's technique must incorporate a strategy for avoiding the lower bar (Figure 1b). When performing backward rotating dismounts, such as the double layout somersault dismount, the gymnast can either straddle the legs to avoid the lower bar or increase the angle of hip flexion (Figure 1b).

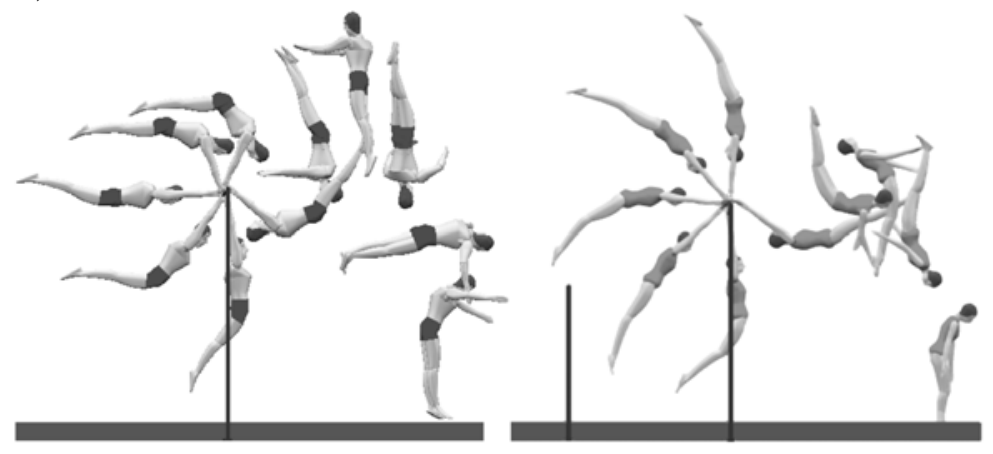

Figure 1. Double layout somersault dismounts (a) with twist from the high bar and (b) with a hyperextended body from the asymmetric bars. 
Performing a double layout somersault dismount in the straight position requires enough angular momentum to produce 1.75 somersaults during flight (or slightly less since the gymnast is short of the vertical on landing). From the graphics sequences in Figure 1 it might be expected that the female gymnast requires less normalised angular momentum than her male equivalent since a hyper-extended configuration is usually adopted in flight. Although Arampatzis and Brüggemann (1999) reported lower mean normalised (for mass) angular momentum values for dismounts from the a-bars compared to the high bar, the type of dismounts performed is unclear. The graphic of the final giant circle presented suggests that these dismounts were performed with a tucked body shape rather than a layout.

Hiley and Yeadon (2003a) calculated the margin for error when timing the release for dismounts from the high bar. The margin for error was quantified in terms of the release window during which time the gymnast has suitable linear and angular momentum for performing the double layout dismount. If the gymnast releases at any point during this window he will have sufficient angular momentum and flight time to complete the dismount. The release window was expressed in ms and the margin for error was calculated as \pm half the release window time. For consistency of performance it is necessary that the margin of error in release timing is large enough to encompass the timing precision of a gymnast. By definition there are consequences of failing to release the bar within the release window. An early release, before the release window has started, is likely to be characterised by insufficient time of flight leading to insufficient somersault rotation and excessive travel away from the bar. Releasing after the release window has ended is characterised by insufficient angular momentum and insufficient travel leading to a risk of striking the bar during flight. It might be expected that gymnasts with larger margins for error will be able to land their dismounts more consistently. Determining the margins for error of performances may give some insight into the required timing precision.

Hiley and Yeadon (2003a) showed that the technique adopted in the backward giant circle leading up to release influenced the size of the release window. It was shown that the "scooped" backward giant circle technique (Figure 1a) flattened the path of the mass centre leading up to release, resulting in a larger release window than for a more "traditional" technique (where the gymnast adopts a more extended configuration when passing through the highest point of the giant circle). In particular, the size of the release window was strongly correlated with the amount of hyper-extension of the gymnast when passing through the lowest point of the final giant circle. Since female gymnasts must adjust their technique to avoid the lower bar, it is not clear how the size of the release windows will be affected.

The aim of this study was to determine the release windows for female gymnasts performing double layout somersault dismounts from the a-bars at the Sydney 2000 Olympic Games. An additional aim was to determine how the technique of the female gymnasts differ from those of their male counterparts performing the same dismount and the likely effect on the size of release window.

\section{Methods}

Subsections in Methods follow the protocol used to determine the release windows for female gymnasts. Initially data collection was carried out in which Olympic performances were recorded and the data processed for subsequent use with computer simulation models. The models were then used to obtain matching simulations of the actual performances and were in turn used to determine the release windows. 


\section{Data collection}

All asymmetric bar performances from the Sydney 2000 Olympic games were recorded using two digital video cameras (Sony Digital Handycam DCR-VX1000E), operating at $50 \mathrm{~Hz}$ with shutter speeds of $1 / 600 \mathrm{~s}$. The two cameras were located $8 \mathrm{~m}$ above the landing surface and $30 \mathrm{~m}$ and $37 \mathrm{~m}$ from the a-bars with a camera axis intersection angle of $66^{\circ}$. Prior to the start of each competition a calibration structure comprising 30 spheres of diameter $0.10 \mathrm{~m}$ spanning a volume measuring $3 \mathrm{~m} \times 4.5 \mathrm{~m} \times$ $4 \mathrm{~m}$ was positioned so as to include a giant circle and dismount from the upper bar.

The centres of the calibration spheres were digitised in five video fields from both camera views. The performances of the nine highest scoring gymnasts who passed the low bar with legs together in the giant circle before releasing for a double layout somersault dismount were selected for analysis. The last $3 / 4$ backward giant circle and the dismount were digitised for each subject. In each of the movement fields the centre of the hand, elbow, shoulder, hip, knee and ankle joint centres and toes on each side of the body were digitised along with the centre of the gymnast's head and the centre of the high bar midway between the gymnast's hands. The data obtained from digitising the images of the calibration spheres and their known locations were used to calculate the 11 Direct Linear Transformation parameters for each of the cameras (Abdel-Aziz and Karara, 1971). The two sets of digitised movement data were synchronised using the method of Yeadon and King (1999). Synchronised digitised coordinate data from each camera view along with the camera parameters were used to reconstruct the threedimensional locations of the body landmarks using the Direct Linear Transformation. Joint angles for the left and right sides were averaged to produce input for a planar simulation model. Quintic splines (Wood and Jennings, 1979) were used to fit the orientation and joint angle time histories so that derivatives could be obtained (Yeadon, 1990a).

A set of anthropometric measurements of a "mean" elite female gymnast was obtained as the mean measurements taken from eight Romanian international gymnasts. These mean values were then scaled for each of the nine competitors using segment lengths and widths obtained from the video digitisation and inertia parameters were calculated using the model of Yeadon (1990b). The normalised angular momentum about the mass centre during the dismount was calculated for each competitor (Yeadon, 1990c). The time of flight was determined from the field before there was clear space between the gymnast's hands and the bar to the field before contact between the gymnast's feet and the landing mat. The horizontal and vertical displacements of the mass centre during flight were used to calculate the horizontal and vertical velocities at release using a least squares fit and assuming constant acceleration.

Simulation model

A four segment planar model of a gymnast comprising arm, torso, thigh and lower leg segments was used to simulate the movement around the bar (Hiley and Yeadon, 2003b). The high bar and the gymnast's shoulder structure were modelled as damped linear springs (Figure 2). The spring at the shoulder represented the increase in length of the gymnast between the wrist and the hip (i.e. not just the stretch at the shoulder joint). In addition to the shoulder spring, there was a parameter that governed the extent to which the torso segment lengthened as the shoulder elevation angle was increased. 


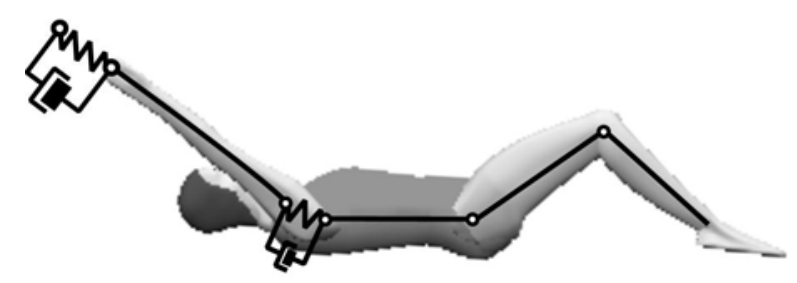

Figure 2. The four segment gymnast / high bar simulation model with damped springs representing bar and shoulder elasticity.

Input to the simulation model comprised the segmental inertia parameters, the stiffness and damping coefficients of the bar and shoulder springs, the initial displacement and velocity of the bar, the initial angular velocity of the arm, the initial orientation of the arm and the joint angle time histories in the form of quintic splines obtained from the video analysis. Output from the model comprised the time histories of the horizontal and vertical bar displacements, the linear and angular momentum of the model and the rotation angle $\phi$ (the angle from the vertical of the line joining the neutral bar position to the mass centre).

The equations of motion were derived using Newton's Second Law and by taking moments about the neutral bar position and the segment mass centres. The angular momentum of the body about its mass centre was calculated as:

$$
\mathrm{h}=\sum_{\mathrm{i}=1}^{4}\left(\mathrm{I}_{\mathrm{i}} \dot{\phi}_{\mathrm{i}}+\mathrm{m}_{\mathrm{i}}\left(\dot{\mathrm{Z}}_{\mathrm{i}} \mathrm{X}_{\mathrm{i}}-\dot{\mathrm{X}}_{\mathrm{i}} \mathrm{Z}_{\mathrm{i}}\right)\right)
$$

where $\mathrm{X}_{\mathrm{i}}=\left(\mathrm{x}_{\mathrm{i}}-\mathrm{X}_{\mathrm{cm}}\right), \mathrm{Z}_{\mathrm{i}}=\left(\mathrm{z}_{\mathrm{i}}-\mathrm{z}_{\mathrm{cm}}\right),\left(\mathrm{x}_{\mathrm{cm}}, \mathrm{z}_{\mathrm{cm}}\right)$ = whole body mass centre location, $\mathrm{m}_{\mathrm{i}}=$ segmental mass, $\mathrm{I}_{\mathrm{i}}=$ segmental moment of inertia, $\dot{\phi}_{\mathrm{i}}=$ segmental angular velocity.

The angular momentum at release was normalised by dividing by $2 \pi$ times the moment of inertia of the body about its mass centre when straight and multiplying by the flight time to give the equivalent number of straight somersaults in the subsequent flight phase. The time of flight of a simulation was calculated from the release and landing heights of the mass centre and the vertical velocity at release using the equation for constant acceleration under gravity. The height of the mass centre on landing was taken from the video analysis of each gymnast.

\section{Matching Simulations}

In order to determine the release window using the simulation model a close match between the simulated and recorded performances was required. The simulation model was implemented with the Simulated Annealing optimisation algorithm (Goffe et al., 1994). A cost function $F$ was established to measure the difference between the recorded performance and a simulation of this performance as defined in equation (2):

$$
\mathrm{F}=\phi+80\left(\mathrm{x}_{\mathrm{b}}+\mathrm{z}_{\mathrm{b}}\right)+20\left(\mathrm{~h}+\dot{\mathrm{x}}_{\mathrm{cm}}+\dot{\mathrm{z}}_{\mathrm{cm}}\right)+5 \phi_{\mathrm{o}}
$$

where $\phi=$ root mean squared (rms) difference in degrees between recorded and simulated rotation angle, $\mathrm{x}_{\mathrm{b}}, \mathrm{z}_{\mathrm{b}}=$ the rms differences between recorded and simulated bar displacements, $\mathrm{h}=$ absolute difference in normalised angular momentum at release between simulation and actual performance, $\dot{\mathrm{x}}_{\mathrm{cm}}, \dot{\mathrm{z}}_{\mathrm{cm}}=$ absolute differences in linear velocity at release between simulation and actual performance, $\phi_{0}=$ absolute difference in initial rotation angle between simulation and actual performance. The weightings of the cost function $\mathrm{F}$ shown in equation (2) were chosen so that each of the seven 
components of the cost function made approximately equal contributions since they were considered to be of equal importance.

Since the aim of the matching process was to provide close agreement between the simulation and the actual performance leading up to release only the last $135^{\circ}$ of the final giant circle was simulated. The subject-specific inertia parameters calculated for each of the nine gymnasts were used in the simulation model. The initial conditions, including the initial angle, angular velocity and bar displacements, for each simulation were taken from the corresponding video analysis. During the optimisation the following parameters were allowed to vary in order to improve the match between the recorded and simulated performance. The vertical bar stiffness was allowed to vary between $13500 \mathrm{~N} \cdot \mathrm{m}^{-1}$ and $19286 \mathrm{~N} \cdot \mathrm{m}^{-1}$ to conform with the specifications of the International Gymnastics Federation (FIG, 2000). The horizontal bar stiffness was allowed to vary between $10800 \mathrm{~N} . \mathrm{m}^{-1}$ and $19286 \mathrm{~N} . \mathrm{m}^{-1}$ since it has been shown that the bar can be less stiff in this direction (Kerwin and Hiley, 2003). The damping coefficient of the bar was allowed to vary between 0 N.s.m ${ }^{-1}$ and 1000 N.s.m ${ }^{-1}$. The stiffness and damping coefficients of the shoulder spring were allowed to vary over wider ranges than those of the bar springs, between $0 \mathrm{~N} . \mathrm{m}^{-1}$ and $40000 \mathrm{~N} . \mathrm{m}^{-1}$ and $0 \mathrm{~N} . \mathrm{s} . \mathrm{m}^{-1}$ and 10000 N.s.m ${ }^{-1}$, respectively, since there was less information available regarding these parameters. The masses of the arms and legs were allowed to vary independently, since they were based on scaling from segment lengths obtained from the video analysis, and the torso mass was adjusted to maintain whole body mass. The torso length parameter was allowed to vary by up to $0.1 \mathrm{~m}$. In addition small variations in the initial conditions, rotation angle and angular velocity, were permitted to compensate for any digitisation errors propagated in their calculation.

\section{Release Windows}

Once the optimisation procedure had provided a simulation to match the video performance of the final $135^{\circ}$ of rotation leading up to the release, the matching simulation for each gymnast was continued beyond the point of release so that a release window could be determined. It was assumed that the gymnast maintained contact with the high bar and continued with the same joint angle changes that occurred after release. The release window was defined as the period of time for which the model possessed normalised angular momentum within $\pm 10 \%$ of the range of actual release values, landed with the mass centre between $1.0 \mathrm{~m}$ and $3.0 \mathrm{~m}$ from the bar and had a time of flight of at least $0.9 \mathrm{~s}$. The angular momentum limits of $\pm 10 \%$ were chosen so that the gymnast would be able to make compensatory configurational changes in flight and successfully land the double layout somersault dismount (Hiley and Yeadon, 2003a) The range of landing distances was based on the mean range of recorded performances \pm two standard deviations. Similarly the minimum time of flight was based on the average flight time minus $10 \%$. One outlier (not included in the average) had a time of flight of 0.9s. It was speculated that this gymnast was close to the limit of performance. For this individual the lower limit of the time of flight was reduced to 0.89s to allow a window to be obtained. The release window was allowed to start before and end after the actual release of the gymnast so long as the above constraints were satisfied.

The relationship between gymnast configuration and magnitude of release window was determined by regressing the sum of the flexion and extension angles at the hip and shoulder joints at the highest point of the final giant circle against the size of the release window. This was repeated for the lowest point of the giant circle. The highest and lowest points of the giant circle occurred when the gymnast's mass centre passed directly above or below the neutral bar position, respectively. 
The release windows for the a-bar dismounts were compared with the windows of male gymnasts in the 2000 Olympic high bar competition.

\section{Results}

The information from the video analysis was used to give the following results. The reconstruction error for the video analysis of the $3 \mathrm{~m} \times 4.5 \mathrm{~m} \times 4 \mathrm{~m}$ calibration volume was calculated to be $0.013 \mathrm{~m}$ in each coordinate, with the field of view spanning more than $7 \mathrm{~m}$. The values for the normalised angular momentum and the vertical velocity at release for the female gymnasts were generally smaller than those of the male gymnasts using the traditional and the scooped backward giant circles (Table 1). However, in some individual cases the normalised angular momentum achieved by the female gymnasts was comparable with that of the male gymnasts. The horizontal velocity at release was smaller than that of the male gymnasts who performed traditional backward giant circles.

Table 1. Velocity of the mass centre and normalised angular momentum about the mass centre at release

\begin{tabular}{|c|c|c|c|}
\hline $\begin{array}{c}\text { competitor } \\
\text { (no.) }\end{array}$ & $\begin{array}{c}\text { horizontal } \\
\text { velocity } \\
\left({\mathrm{m} . \mathrm{s}^{-1}}^{-1}\right.\end{array}$ & $\begin{array}{c}\text { vertical } \\
\text { velocity } \\
\left({\mathrm{m} . \mathrm{s}^{-1}}^{-}\right.\end{array}$ & $\begin{array}{c}\text { angular momentum } \\
\text { (straight } \\
\text { somersaults) }\end{array}$ \\
\hline 300 & 0.95 & 3.56 & 1.49 \\
\hline 314 & 0.69 & 2.99 & 1.53 \\
\hline 331 & 1.27 & 3.97 & 1.58 \\
\hline 353 & 0.96 & 3.85 & 1.44 \\
\hline 357 & 0.95 & 3.59 & 1.49 \\
\hline 364 & 0.97 & 3.47 & 1.49 \\
\hline 367 & 1.74 & 3.69 & 1.57 \\
\hline 386 & 1.01 & 3.80 & 1.59 \\
\hline 390 & 1.07 & 4.27 & $\mathbf{1 . 5 2}$ \\
\hline mean & $\mathbf{1 . 0 9}$ & $\mathbf{3 . 6 8}$ & 1.58 \\
\hline traditional & 2.11 & 4.89 & 1.65 \\
\hline scooped & 1.27 & 4.38 & \\
\hline
\end{tabular}

Note: mean values for traditional and scooped circles are taken from the study on high bar dismounts by Hiley and Yeadon (2003a)

Over the nine performances studied the simulation model was able to match the recorded rotation angle during the final $135^{\circ}$ leading up to release to within $1.2^{\circ} \mathrm{rms}$ difference, and the horizontal and vertical displacements of the bar to within $0.011 \mathrm{~m}$ rms difference (Figure 3). The simulation model matched the normalised angular momentum and the linear velocities at release to within 1\%. For the nine performances the mean stiffness coefficient (vertical and horizontal combined) of the bar obtained in the matching procedure was $14669 \mathrm{~N} . \mathrm{m}^{-1}$, which lay within the limits as set out by the FIG (2000). It was found that on average the bar was 19\% less stiff in the horizontal direction. The average damping coefficient for the bar was $55 \mathrm{~N} . \mathrm{m} . \mathrm{s}^{-1}$. The average torso length parameter and the average stiffness and damping coefficients of the spring 
at the shoulder were less than $0.01 \mathrm{~m}$ and $25261 \mathrm{~N}^{-\mathrm{m}^{-1}}$ and $1003 \mathrm{~N} . \mathrm{s} . \mathrm{m}^{-1}$, respectively. The corresponding values for the male gymnasts were $26129 \mathrm{~N} . \mathrm{m}^{-1}$ and $174 \mathrm{~N} . \mathrm{s} . \mathrm{m}^{-1}$ for the bar spring, $0.05 \mathrm{~m}$ for the torso length parameter and 56780 N.m ${ }^{-1}$ and 12904 N.s.m ${ }^{1}$ for the shoulder spring coefficients.
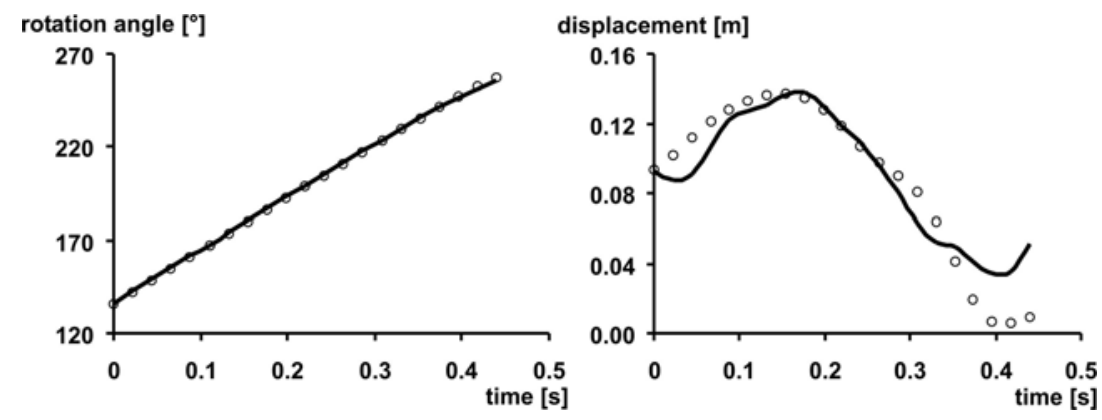

Figure 3. Typical matches between simulation (solid line) and actual performance (circles) for (a) whole body rotation angle and (b) net bar displacement.

The release windows determined by simulation for the nine female gymnasts along with the average values calculated for the male gymnasts are presented in Table 2. The mean release window for the female gymnasts $(n=9)$ was 69 milliseconds (range 43 $102 \mathrm{~ms}$ ) whereas the mean windows for the male gymnasts were $81 \mathrm{~ms}$ (range $79-84$ $\mathrm{ms})$ and $127 \mathrm{~ms}$ (range $95-157 \mathrm{~ms})$ for the traditional $(\mathrm{n}=3)$ and scooped $(\mathrm{n}=8)$ techniques respectively.

Table 2. Sum of the flexion and extension angles at the hip and shoulder at the highest and lowest points of the giant circle

\begin{tabular}{|c|c|c|c|c|}
\hline $\begin{array}{c}\text { competitor } \\
\text { (no.) }\end{array}$ & $\begin{array}{c}\text { sum of } \\
\text { angles at } \\
\text { highest } \\
\text { point } \\
\left(^{\circ}\right)\end{array}$ & $\begin{array}{c}\text { sum of } \\
\text { angles at } \\
\text { lowest } \\
\text { point } \\
\left(^{\circ}\right)\end{array}$ & $\begin{array}{c}\text { release } \\
\text { window } \\
(\mathrm{ms})\end{array}$ & $\begin{array}{c}\text { release } \\
\text { window } \\
\left(^{\circ}\right)\end{array}$ \\
\hline 300 & -16 & -26 & 62 & 15 \\
\hline 314 & -8 & -15 & 43 & 9 \\
\hline 331 & 2 & -23 & 77 & 21 \\
\hline 353 & 15 & -33 & 98 & 27 \\
\hline 357 & 0 & -29 & 67 & 16 \\
\hline 364 & 6 & -7 & 102 & 25 \\
\hline 367 & -31 & -16 & 68 & 15 \\
\hline 386 & 26 & -38 & 61 & 14 \\
\hline 390 & 3 & -19 & 48 & 12 \\
\hline mean & $\mathbf{3}$ & -23 & $\mathbf{6 9}$ & $\mathbf{1 7}$ \\
\hline traditional & 9 & -12 & 81 & 26 \\
\hline scooped & 125 & -40 & 127 & 46 \\
\hline
\end{tabular}

Note: (a) angles are defined away from a handstand position with negative angles corresponding to an arched configuration

(b) last column expresses release window in terms of the change in rotation angle 
There appeared to be no relationship between the sum of the flexion and extension angles at the hip and shoulder at the highest and lowest points and the size of the release window $\left(\mathrm{R}^{2}=0.07, \mathrm{p}=0.48\right.$ and $\mathrm{R}^{2}=0.00, \mathrm{p}=0.87$, respectively).

\section{Discussion}

Computer simulation is a powerful tool for investigating elite technique in sports movements. Before simulation can be used for this purpose, however, it is essential that the ability of the model to closely match an actual performance is investigated. Often such an investigation leads to modifications of the model: for example the way in which elastic elements are represented. Without a quantitative evaluation of a model, the confidence that should be placed on the results of simulation is uncertain. In this study the simulation model was able to match the linear and angular momentum of nine giant circles to within 1\%. These simulations gave release windows ranging from $43 \mathrm{~ms}$ to $102 \mathrm{~ms}$ corresponding to a margin for error in the range $22 \mathrm{~ms}$ to $51 \mathrm{~ms}$. At this point it is appropriate to note that "margin for error" is a misnomer in the sense that all performances within the release window are acceptable and are therefore not in error. Perhaps a better term would be "margin of variation" since this would fit in better with the idea that variation is a necessary part of performance (Newell and Corcos, 1993).

It was speculated that since female gymnasts used backward giant circling techniques similar to the traditional technique used by a minority of male gymnasts, they would have comparable release windows. To determine the release window for a gymnast requires knowledge of what would have happened had the bar been released later than in the actual performance. Using a computer simulation model provided a means for investigating this hypothetical scenario. This approach is limited by the assumption of configuration changes when releasing later than in the actual performance and also by the somewhat arbitrary criteria for a successful dismount. Although altering the criteria may lead to changes in the size of the release windows, it is likely that similar changes would occur across all gymnasts and so the findings would not change.

The spring parameters obtained for the bar from the matching simulations lay within the bounds set out for the apparatus by the FIG norms (2000). The parameter values obtained for the spring at the shoulder for the female gymnasts were considerably smaller than those obtained for the male gymnasts. The spring is used to represent the stretch in the gymnast occurring between the wrist and the hip, not just the stretch in the shoulder region. It can also be seen that the amount the torso lengthened during shoulder elevation was different between the two sets of gymnasts. The optimisation procedure was used to obtain a close match of the parameters in the cost function (equation 2) but there appears to have been a degree of interplay between the shoulder stiffness and damping and the torso lengthening parameters. If individual figures for the amount the torso lengthened as the shoulder elevation angle increased were available it is likely a more meaningful comparison could be made between the female and male shoulder spring parameters.

The mean release windows for the female gymnasts and the male gymnasts using the traditional technique were comparable (Table 2). All of the male traditional release windows fell within the range of release windows obtained for the female gymnasts. It may be expected that if more than three male gymnasts had used the traditional technique a wider range of release windows would have been found. The reason why the a-bar performances had release windows similar to the traditional male gymnasts may be understood by looking at the path of the mass centre during the final giant circle for typical male and female dismounts (Figure 4). The dashed circle in each case was drawn with its centre at the neutral bar position and passing through the mass centre of 
the gymnast at the lowest point. In the traditional technique and the a-bars dismount the path of the mass centre is almost circular and the velocity direction changes rapidly as the gymnast approaches release. The paths of the mass centre are not perfectly circular due to the displacement of the bar and the final actions at the hip and shoulder joints. The mean change in the direction of mass centre velocity during the release window was $22.2^{\circ} \pm 5.7^{\circ}$ for the a-bars and $22.8^{\circ} \pm 1.4^{\circ}$ for the traditional technique dismounts. In contrast in the scooped technique there is a flattening of the path of the mass centre and the velocity direction changes less rapidly as the gymnast approaches release with a mean change over the release window of $10.3^{\circ} \pm 6.2^{\circ}$. The corresponding changes in rotation angle over the release window were also similar for the a-bars dismounts and the traditional technique with mean values of $17.1^{\circ} \pm 5.9^{\circ}$ and $26.3^{\circ} \pm 1.5^{\circ}$ respectively. Again the mean value for the scooped technique $\left(46.1^{\circ} \pm 9.7^{\circ}\right)$ was quite different from the other two groups and reflects the larger release windows of these gymnasts. The roughly circular mass centre path of the traditional circles led to the release window being limited primarily by the direction of the mass centre velocity (Table 3). That is, at the upper limit of the window there was insufficient horizontal velocity to carry the gymnast safely away from the bar. In contrast the flattened path of the mass centre for the scooped circles resulted in less constraints with regard to velocity direction, with the upper limit of the release window being determined primarily by insufficient angular momentum. As expected the lower limits to the release windows for the majority of dismounts corresponded to excessive travel or insufficient time of flight. The limiting variables for four of the a-bars release windows were the same as those for the traditional dismounts while the remainder were not characteristic of the majority of scooped dismounts (Table 3). All the release windows had the upper limit of the window determined by either insufficient travel or insufficient angular momentum.
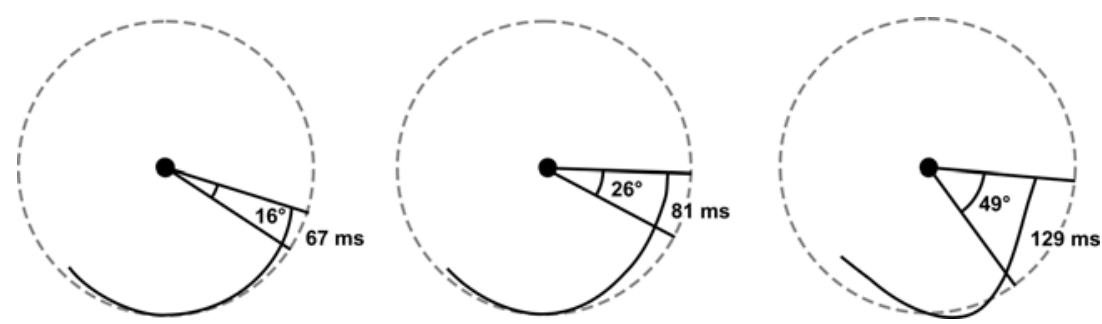

Figure 4. Typical paths of the mass centre during the last half of the backward giant circle leading up to release for one female gymnast, one male gymnast using a traditional technique and one male gymnast using a scooped technique. The flatter final part of the scooped path results in a more consistent flight trajectory and a larger release window. 
Table 3. The parameters which limited the release window at the start and end of the release window

\begin{tabular}{|c|c|c|c|c|c|c|}
\hline \multirow{2}{*}{$\begin{array}{l}\text { trial } \\
\text { (no.) }\end{array}$} & \multirow{2}{*}{$\begin{array}{c}\text { release } \\
\text { window } \\
(\mathrm{ms})\end{array}$} & \multirow{2}{*}{$\begin{array}{c}\text { release } \\
\text { angle } \\
\left(^{\circ}\right)\end{array}$} & \multirow{2}{*}{$\begin{array}{c}\text { window } \\
\text { start } \\
\left({ }^{\circ}\right)\end{array}$} & \multirow{2}{*}{$\begin{array}{c}\text { window } \\
\text { end } \\
\left(^{\circ}\right)\end{array}$} & \multicolumn{2}{|c|}{ release window limited by } \\
\hline & & & & & start & end \\
\hline 300 & 62 & 254 & 243 & 258 & excessive AM & insufficient AM \\
\hline 314 & 43 & 258 & 251 & 261 & excessive AM & insufficient AM \\
\hline 331 & 77 & 250 & 238 & 258 & excessive travel & insufficient AM \\
\hline 353 & 98 & 248 & 230 & 257 & insufficient flight time & insufficient travel \\
\hline 357 & 67 & 247 & 237 & 253 & insufficient flight time & insufficient travel \\
\hline 364 & 102 & 253 & 235 & 259 & insufficient flight time & insufficient travel \\
\hline 367 & 68 & 247 & 242 & 258 & excessive travel & insufficient travel \\
\hline 386 & 61 & 241 & 233 & 247 & insufficient flight time & insufficient travel \\
\hline 390 & 48 & 250 & 243 & 255 & excessive AM & insufficient AM \\
\hline traditional x 3 & & & & & insufficient flight time & insufficient travel \\
\hline scooped x 4 & & & & & excessive travel & insufficient AM \\
\hline scooped x 2 & & & & & insufficient flight time & insufficient AM \\
\hline scooped x 1 & & & & & excessive AM & insufficient AM \\
\hline scooped x 1 & & & & & excessive travel & insufficient travel \\
\hline
\end{tabular}

Note: $\mathrm{AM}=$ angular momentum

The angular momentum for the dismount is influenced by the gymnast's actions at the hip and shoulder joints during the giant circle leading up to release. It was found that the female gymnasts' technique was affected by the necessity to clear the lower bar. For the female gymnasts maximum hip hyper-extension occurred after the lowest point of the circle (Figure 5a), whilst for the male gymnasts it occurred before the lowest point. A similar relationship was found for the shoulder angle (Figure 5b). Flexing the hip over a larger range of motion may be expected to increase the gymnast's angular momentum. In the present study none of the female gymnasts used a scooped technique, or a technique that produced a similar effect on the path of the mass centre leading up to release. This may account for the lack of correlation between joint angles and release window for the female gymnasts.

The scooped technique is characterised by a large hyper-extension at the hip as the gymnast passes through the lowest point of the circle. The subsequent rapid hip flexion (Figure 5) helps produce the loading on the bar associated with the flattened path of the mass centre. It is speculated that achieving a larger hyper-extension at the hip earlier in the giant circle may help increase the size of a female gymnast's window and lead to greater angular momentum. Future investigations could be carried out using the simulation model to determine whether this can be achieved given the constraint of the lower bar. 

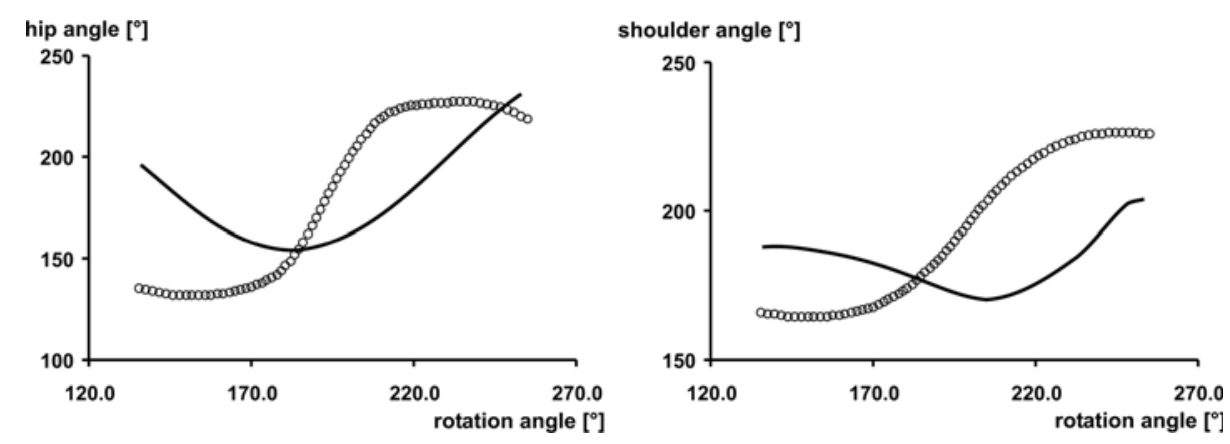

Figure 5. Typical hip (a) and shoulder (b) joint angle time histories for female (solid line) and male gymnasts (circles) over the last $135^{\circ}$ of the giant circle leading up to release.

The majority of female gymnasts performing the double layout dismount adopted a hyper-extended "arched" position during flight (Figure 1b). As is the trend with male dismounts the female gymnasts are introducing a full twist into the double layout dismount. As the number of twists increases so must the time the gymnast spends in the straight position which is more efficient for twisting than a hyper-extended position. In order to achieve this the gymnast will require either a longer time of flight or more angular momentum. Increasing the time of flight or the angular momentum of the gymnast at release is likely to reduce the size of the release window, as shown by Hiley and Yeadon (in press). Therefore the technique in the final giant circle prior to release may need to be developed in order to maintain a sufficient release window despite the increase in angular velocity.

In general the techniques used by the female gymnasts produced similar results to those of the traditional technique used by male gymnasts. However, the limiting factor to the size of the release window was not consistent between gymnasts and may have been the result of variations in the timing of the final shoulder extension and hip flexion. This raises questions regarding the gymnast's ability to reproduce the same technique and release window on repeated trials. Were the gymnasts with the larger release windows more accomplished and better able to time their final actions correctly or was 43 ms a sufficiently large release window for consistent timing of the release? This could not be determined from the present study and would require the calculation of a gymnast's release window from repeated trials.

\section{Acknowledgements}

The authors wish to acknowledge the support of the British Gymnastics World Class Programme, Sport England, UK Sport, Pfitzer and the International Olympic Committee Medical Commission.

\section{References}

Abdel-Aziz, Y.I., and Karara, H.M. (1971). Direct linear transformation from comparator coordinates into object space coordinates in close-range photogrammetry. ASP Symposium on Close-Range Photogrammetry (pp. 1-18). Falls Church, VA: American Society of Photogrammetry.

Arampatzis, D. and Brüggemann, G-P. (1999). Mechanical and energetic processes during the giant swing exercise before dismount and flight elements on the high bar and uneven parallel bars. Journal of Biomechanics, 32, 811-820.

Fédération Internationale de Gymnastique 2000. Manual apparatus norms. Part IV testing procedures. F.I.G. Moutier. Switzerland. 
Goffe, W.L., Ferrier, G.D. and Rogers, J. (1994). Global optimization of statistical functions with simulated annealing. Journal of Econometrics, 60, 65-99.

Hiley, M.J. and Yeadon, M.R. (2003a). The margin for error when releasing the high bar for dismounts. Journal of Biomechanics, 36, 313-319.

Hiley, M.J. and Yeadon, M.R. (2003b). Optimum technique for generating angular momentum in accelerated backward giant circles prior to a dismount. Journal of Applied Biomechanics, 19, 119-130.

Hiley, M.J. and Yeadon, M.R. (in press). Maximal dismounts from high bar. Journal of Biomechanics.

Kerwin, D.G. and Hiley, M.J. (2003). Estimation of reaction forces in high bar swinging. Sports Engineering, 6, 21-30.

Newell, K.M. and Corcos, D.M. (1993). Variability and motor control. Human Kinetics. Champaign, IL.

Wood, G.A. and Jennings, L.S. (1979). On the use of spline functions for data smoothing. Journal of Biomechanics, 12, 477-479.

Yeadon, M.R. (1990a). The simulation of aerial movement - I. The determination of orientation angles from film data. Journal of Biomechanics, 23, 59-66.

Yeadon, M.R. (1990b). The simulation of aerial movement - II. A mathematical inertia model of the human body. Journal of Biomechanics, 23, 67-74.

Yeadon, M.R. (1990c). The simulation of aerial movement- III. The determination of the angular momentum of the human body. Journal of Biomechanics, 23, 75-83.

Yeadon, M.R. and King, M.A. (1999). A method for synchronising digitised video data. Journal of Biomechanics, 32, 983-986. 